\title{
UNA OBRA DE CONTRARIS: LA IMPORTÀNCIA D'HERÀCLIT EN LLORENÇ VILLALONGA ${ }^{1}$
}

\author{
ELOI CREUS \\ Universitat de Barcelona \\ eloicreus@ub.edu \\ ORCID: 0000-0003-0640-3460
}

RESUM

En aquest article es repassa la presència del pensador Heràclit en l'obra de Llorenç Villalonga i s'analitza com funcionen els mecanismes de la tradició clàssica a través de l'exemple que forneixen les mencions al pensador d'Efes en el corpus de textos que publicà l'escriptor mallorquí. Per tal d'entendre més fàcilment el perquè de l'interès de Villalonga en Heràclit, s'estudia, primer, la formació intel-lectual i el context històric de l'escriptor. Després, es sotmeten a un examen conscient les aparicions, directes o indirectes, de les idees del pensador grec en l'obra de Villalonga.

PARAULES CLAU: Tradició clàssica, pensament clàssic, Literatura catalana, segle XX, Villalonga, Heràclit.

\section{A WORK OF OPPOSITES: THE IMPORTANCE OF HERACLITUS IN LLORENÇ VILLALONGA}

\section{ABSTRACT}

This paper focuses on the presence of thinker Heraclitus in Llorenç Vilallonga's oeuvre, and analyses how the mechanisms of the classical tradition work in so many instances of his extensive output. To better understand the reasons of Villalonga's interest in Heraclitus, it first retraces the author's background, both historical and intellectual. After which, it proceeds to a perusal of all the occurrences, either direct or indirect, of the Greek thinker's ideas in the Majorcan's works.

KEYWORDS: Classical tradition, Classical thought, Catalan literature, $20^{\text {th }}$ century, Villalonga, Heraclitus.

L'obra narrativa i dramàtica de Llorenç Villalonga (1897-1980) és plena de referències a temes i personatges del món clàssic. La freqüència d'aparició d'elements de la tradició clàssica no és casual i no pocs estudiosos s'hi han acostat $i$ han estudiat el tema des de diferents perspectives, centrant-se sobretot en els mites de Fedra i d'Aquil·les. ${ }^{2}$ Jo mateix he volgut destacar en d'altres llocs, especialment, la importància de les figures del món del pensament grec en l'obra de l'autor mallorquí. ${ }^{3}$

\footnotetext{
${ }^{1}$ Voldria dedicar aquest modest article al Dr. Pau Gilabert, heraclitià convençut, en motiu de la seva jubilació.

2 Vg. Alzamora (1999), Bosch (1979, 1981, 1988, 1989, 1991, 1992 i 2007), Cabré (2007), Morenilla (2015) i Ragué Arias (1987).

${ }^{3}$ Creus $(2017,2018$ i 2019).
} 
En aquesta ocasió, em proposo centrar-me en un dels autors sorprenentment més citats, directament o indirecta, per part de Villalonga: Heràclit. I dic sorprenent no perquè aquest pensador no estigués de moda durant el segle $x x$, al contrari, ${ }^{4}$ sinó perquè, donat el seu caràcter irremeiablement fragmentari, no és un pensador que esperaríem trobar en l'obra d'un autor com Villalonga, de formació clàssica quasi inexistent.

Efectivament, l'autor mallorquí era psiquiatra i tenia uns coneixements molt bàsics de llatí i no coneixia en absolut el grec. La seva formació, com hem dit, era de base gàl-lica, enamorat com estava de la França del segles de les llums, de la Raó cartesiana sobre la qual va bastir la construcció de la majoria de les seves narracions, enfrontant-la a l'absurd d'una vida il·lògica en tant que abocada a la mort.

És a través de models francesos que sembla que arribà a interessar-se per Grècia. ${ }^{5}$ Per una Grècia molt concreta, molt idíl-lica, la Grècia il·lustrada de marbre blanc. Així, conegué l'obra d'Homer, a qui considerava primitiu, i de Plató, gràcies al qual descobrí Sòcrates, el que per ell era el pare de la filosofia, i també Zenó d'Elea. ${ }^{6}$ De fet, l'impacte de la presència del món grec en la seva obra és fàcilment perceptible repassant el corpus de textos de l'escriptor mallorquí. Amb un primer cop d'ull ja podem veure que escriví dues obres de teatre d'evident tema clàssic, Fedra i Aquil.les o l'impossible, i dos relats breus: Diàlegs socràtics i La Xantipa.

La literatura grega que havia llegit, sempre en traducció, era ben minsa. Sabem, precisament pel relat alternatiu que proposa Villalonga d'un dels passatges de la Ilíada a Aquil·les o l'impossible, que s'ocupà d'Homer, en versió francesa de Leconte de Lisle. ${ }^{7}$ També sabem per La Xantipa, que llegí i afusellà el Protàgoras de Plató, ${ }^{8}$ de qui també llegí el Parmènides i el Cràtil. ${ }^{9}$ Aquí i allà trobem alguna citació en llatí de Virgili, de les Bucòliques i l'Eneida i poca cosa més. ${ }^{10} \mathrm{La}$ resta li venia per tradició indirecta i molt sovint amb mancances importants. Villalonga no era un intel-lectual comme il faut. Era desmenjat i sovint citava malament. Així, només per posar un exemple, en una ocasió confon Aristòtil amb Aristòfanes:

\footnotetext{
${ }^{4}$ Pensem en la fascinació que sentí Palau i Fabre per Heràclit, que el portaren a escriure, en francès, La claredat d'Heràclit, que es va traduir no fa gaire anys en català, cf. Palau i Fabre (2007). ${ }^{5} \mathrm{Vg}$. Bosch (1981).

${ }^{6}$ Cf. «Homer, si és que realment ha existit, ja que les seves obres pareixen més un aplec de narracions populars, és un primitiu. Sòcrates és com un nouveau riche de sa raó. Imagina't: l'acabava de descobrir» (Bearn o la sala de les nines dins d'El cicle de Bearn: 362).

7 Vg. Cabré (2007: 149).

${ }^{8}$ Cf. Creus (2019).

${ }^{9} \mathrm{Vg}$. Bosch (1988).

${ }^{10} \mathrm{Vg}$. Bosch (1992).
} 
A una de les seves astracanadas, Aristòtil ens mostra els deixebles de Sòcrates aficats dins paners penjats del sòtil, per comptes de tenir idees elevades. Però no es tracta de tenir idees sublims. És suficient procurar tenir idees, ordre, per ara. (Diàlegs socràtics: 183)

Com es veu, tot i no conèixer per via directa el món clàssic i tenir-ne una idea vaga i edulcorada, Villalonga fa un ús conscient i continu de la tradició clàssica, normalment amb voluntat humorística o paròdica, i només en alguns casos els elements de la tradició clàssica són centrals en les seves obres, com en les abans esmentades. ${ }^{11}$

En el cas concret d'Heràclit, trobem que el pensador apareix reiteradament des de l'inici fins al final de la seva producció. Primer, de manera anecdòtica, però sobretot després de la publicació de Desenllaç a Montlleó (1958), la influència del pensador grec, o més ben dit, de la idea que en tenia Villalonga, va prenent més importància.

És clar que Villalonga coneixia Heràclit de segona mà. Tenia la imatge del pensador d'Efes que prevalia cap el segle XIX entre els corrents filosòfics i que encara ara s'ensenya a les escoles de secundària. És a dir, una imatge de manual de filosofia que beu de la tradició lectora de Plató i que amb prou feines coneix els fragments d'Heràclit. Villalonga sens dubte que no hi havia acudit, i, això a banda, és evident que havia arribat tard per conèixer les noves lectures que s'han anat fent del pensador jònic i dels presocràtics en general i que probablement poc haurien interessat l'escriptor mallorquí.

Hem de pensar que Villalonga escriu en un moment en què a Mallorca conviuen dos mons: l'endarreriment i el tancament normals en una illa amb els canvis que provoca la modernitat del segle XX i totes les seves conseqüències: la pèrdua de poder de l'antiga noblesa en mans de la burgesia, el declivi de la influència de l'església, l'arribada del turisme, l'adveniment dels règims totalitaris, les dues guerres mundials, la guerra civil en què Villalonga participà activament com a metge en les files franquistes, etc. Villalonga, doncs, s'educà intel-lectualment en un moment en què el corrent cultural preponderant a finals de segle, el positivisme científic i totes les representacions artístiques que se'n derivaven, com el naturalisme, havien entrat ja feia anys en col-lapse, en un carreró sense sortida: amb una fe sense límits en la ciència experimental i el progrés, que havia de portar al coneixement vertader de les causes primeres de la realitat, el positivisme s'havia vist incapaç de respondre als enigmes de la natura i, per extensió, de l'home, subjecte a canvis i paradoxes constants. ${ }^{12} \mathrm{El}$ substituí un moviment artístic i cultural de caràcter racionalista i antimaterialista representat en al figura d'Anatole France i que considerava la raó l'única facultat

\footnotetext{
11 Així, Fedra en l'obra homònima, Aquil·les a Aquil·les o l'impossible i Sòcrates als Diàlegs socràtics i a La Xantipa.

12 Segueixo Ferrà-Ponç (1997: 19-56).
} 
per entendre el món. ${ }^{13}$ Amb els anys, però, Villalonga s'anà separant de la influència de France, el racionalisme extrem del qual impedia explicar la realitat absoluta de l'home i davant del fracàs del positivisme científic, ${ }^{14}$ de l'agonia de la cultura europea de la qual eren representants France i Proust, l'altre referent de Villalonga, i, sobretot, davant de la situació d'anormalitat històrica que vivia Mallorca, Villalonga, en un cas únic en un autor del segle XX, acabà fent un pas enrere i es declarà hereu d'una tradició clàssica deutora directament de les Lumières. ${ }^{15}$ Tenint en consideració les influències ara esmentades, prengué els valors de la França que pretenia Voltaire: donà un enfocament il-lustrat i humanista de l'art, en què el creador només havia de prendre l'home com a mesura de totes les coses; es presentà com un racionalista cartesià, en tant que la Raó era la facultat de la intel-ligència, l'única fiable davant dels canvis que enganyen els sentits. I és aquí on sembla que començà el seu interès en Heràclit.

Per a Villalonga, Heràclit és el paradigma del pensador que va afirmar per primera vegada que hom no podia confiar l'intel-lecte a la informació provinent dels sentits, sinó que ha de fiar-ho tot a la Raó, única facultat de l'intel·lecte vàlida per arribar a l'aprehensió del món. És a dir, Heràclit era el que Plató deia que era. Així, en la concepció de Villalonga, Heràclit és el precedent primitiu de Descartes, el filòsof del panta rei que pot llegir en el Cràtil de Plató. ${ }^{16}$

Heràclit representava un puntal més del relativisme que defensava Villalonga. Una mirada que posava en dubte l'existència d'una veritat absoluta i definitiva de l'estat de les coses:

Els llibres antics han sofert, en el transcurs dels segles, alteracions profundes. El vell Heràclit ens diu que no podem mirar dues vegades un riu, perquè l'aigua que hi corre no és mai la mateixa. Tot és variable i efímer. ¿Qui podrà estar segur de posseir l'edició definitiva de les coses? (Bearn o la sala de les nines: 540)

Aquesta visió no estàtica del món, d'una realitat canviant és molt preuada per Villalonga, que la fa aparèixer força sovint en les obres, encara que no sempre citi directament Heràclit:

És que en el teu raonament no hi entra el concepte que tot es muda. Tot ho veus estàtic. Suposes que les coses han d'esser immutables i que el que és mutable ja no és cosa. (Diàlegs socràtics: 198)

\footnotetext{
${ }^{13}$ La influència del qual en l'obra de Villalonga hom la pot trobar magníficament explicada en Ferrà-Ponç (1997: 237-262) i Simbor Roig (2011: 69-88).

${ }^{14} \mathrm{Val}$ a dir que no li atorgava ni l'adjectiu de científic: «sols existeix una ciència (ben entès, pels qui l'admeten) que és la teologia, perquè ella ha trobat la causa radical» (Falses memòries: 41).

${ }^{15}$ Per a una detallada concepció novel-lística de Villalonga vegeu, a més del treball citat de Ferrà-Ponç, el capítol «El concepte de novel-la en Villalonga» a Mas i Canals, (2013: 66 i ss).

${ }^{16} \mathrm{Pl}$. Cra. 402a-b: «Diu en algun lloc Heraclit que "tot es mou i res no roman"; compara els éssers al corrent d'un riu i sosté que, "dues vegades no podries entrar en el mateix riu"» (Trad. de Jaume Olives Canals).
} 
Veiem que aquestes són referències a Heràclit que Villalonga utilitza, diguem, per amanir el seu discurs racionalista i antiempíric. És una presència, com hem dit abans, de tipus anecdòtic. On realment trobem la importància d'un autor com Heràclit en l'obra de Villalonga és en la seva concepció narrativa.

Com ja van notar Llompart i Vidal Alcover, ${ }^{17}$ tot o quasi tot l'univers narratiu i dramàtic de Villalonga es fonamenta en l'equilibri entre la unió de contraris. Bàsicament en el combat etern entre la Raó i la no-Raó, l'Absurd, en un conflicte del qual sempre acaba resultant guanyador aquest últim. I és que, si bé Villalonga es va considerar sempre un racionalista, en les seves obres i com a reflex de la seva pròpia experiència, enfrontava la Raó al món caòtic d'una raça humana estúpida i materialista que cíclicament cometia els mateixos errors. Així, el seu món narratiu serà el reflex d'aquesta oposició de mons contraris. Els personatges s'enfrontaran segons les seves tendències racionalistes o el seu comportament irracional. El món rural i inculte s'enfrontarà a l'il·lustrat, i així successivament.

De fet, aquesta manera d'entendre l'art narratiu com una oposició entre dos mons contraris és el fidel reflex de la persona de Villalonga. L'escriptor mallorquí era un home fet de contraris. Ell en si mateix era una contradicció. Racionalista, però pessimista amb la raó. Liberal i il·lustrat, però antiprogressista i totalitarista. Casat amb Teresa Gelabert, i amb una postura conservadora envers l'homosexualitat, tot i no condemnar-la, però amb tendències i gustos ambivalents que podríem qualificar d'homosexuals. Catòlic, però pràcticament agnòstic i anticlerical. Anticatalanista, però amb l'obra pròpia escrita majorment en català perquè el públic el tenia al Principat. La llista podria ser molt llarga.

No ens ha d'estranyar gens, doncs, que Villalonga sentís una atracció natural cap al filòsof que, segons la tradició, entenia el món exactament igual que ell. Així, la permanent mobilitat de la natura, que feia que l'escriptor s'alineés amb la raó i desconfiés dels sentits, es fonamentava segons l'Heràclit que coneix Villalonga, en l'equilibri entre els elements contraris que conformen la natura. Deia Heràclit:

Car sense el greu i l'agut no hi hauria harmonia; ni hi hauria éssers vius sense femella i mascle, que són oposats. ${ }^{18}$

Villalonga no podia conèixer la teoria de contraris a través dels fragments del suposat llibre d'Heràclit. Bosch suposa que «la treu dels Diàlegs de Plató». ${ }^{19}$ Potser també d'alguna lectura d'Aristòtil $0,{ }^{20}$ com sempre, el més probable és que la prengués d'algun autor francès que en recollís les paraules o que el redirigís a les obres dels filòsofs grecs. En tot cas, el mateix Villalonga concebia el món com

\footnotetext{
17 Llompart (1964: 8-15), Vidal Alcover (1965: 10).

${ }^{18}$ Frag. 9AM = 22 A 22 DK. Trad. de Jaume Pòrtulas i Sergi Grau.

${ }^{19}$ Bosch (1981: 163).

${ }^{20}$ Cf. Arist. EE. H I 1235ㄹ 25-29.
} 
un combat entre opcions contràries. La meravella d'un escriptor de la talla de Villalonga, però, és que, en prendre el model clàssic, se l'apropia i en fa una cosa diferent. Així sona Heràclit en versió de Villalonga:

Faran mal i bé. El món és una harmonia de contraris. Veu que mos trobam de bé, vostè i jo, davant es foc? S'acosti més, aquí té una pell d'ovella. És perquè sa nit comença a ésser fresca. Demà hi haurà gelada. Després sortirà es sol, fondrà es crestalls; i ets arbres i ses flors quedaran nets, com a rentats. (Bearn o la sala de les nines: 444)

\section{O encara:}

Entre Déu i Dimoni ha d'existir per força una coordinació, un equilibri. (Ibid: 461)

Villalonga imagina el món com una balança, a cada braç de la qual hi ha un element que pesa exactament el mateix, però de càrrega contrària. L'estabilitat entre aquests dos elements garanteix una harmonia mundial tan perfecta com fràgil. Si quelcom, normalment el progrés positivista, altera el pes d'algun $\mathrm{d}$ 'aquests elements, es produeix la catàstrofe, com passa a les novel·les de l'última producció de Villalonga, el màxim exponent de la qual és una de les últimes novel-les publicades en vida de l'autor, Andrea Victrix, que transcorre en una era de l'esdevenidor en la qual el progrés i un comunisme molt sui generis ha arribat al poder i ha canviat l'equilibri natural de les coses:

Els nombres són exactes, però estúpids, ja que no tenen intencionalitat. Els vocables tenen intenció i esperit, però per això mateix, estan subjectes a una contínua evolució. La prudència aconsellaria una harmonia entre els dos sistemes. Tem, però, que sigui justament l'harmonia el que aquesta era ha perdut. (Andrea Victrix: 60)

Més que potser una balança, que és quelcom pràcticament estàtic, ens valdria més una metàfora musical com la que proposa Ferrà-Ponç: comentant la influència de Proust en l'obra de Villalonga, ve a dir que l'obra de l'autor mallorquí és com una «una clàssica simfonia, les notes oposades vénen a coincidir a la fi i a donar-nos, mitjançant la unió final dels extrems, l'Harmonia» (Ferrà-Ponç 1997: 180).

Si prenem aquesta imatge de la simfonia clàssica, entendrem per què Villalonga considera que els contraris, per llur mateixa condició, no ho són tant, atès que els extrems, com el primer o el quart moviment d'una simfonia clàssica vienesa, malgrat estar frontalment oposats a una i altra banda, estan tan relacionats per un mateix tema musical que s'acaben tocant. Fent servir una expressió ben villalonguiana, on Heràclit ja s'ha difuminat del tot: «els contraris són igual que el lluç que es mossega la coa» (Flo la Vigne: 244).

D'aquí que Odisseu, a Aquil.les o l'impossible, pugui afirmar que «la veritat no és el contrari de la mentida» (58), o que don Toni de Bearn vegi la dualitat Déu-Dimoni com la mateixa cara d'una moneda.

Com que Villalonga entén el món d'aquesta manera «heraclitiana», amb tot el que comporten aquestes cometes, per extensió també la vida i els homes que la 
viuen són considerats des de la mateixa òptica. La vida és entesa per Villalonga, doncs, també com un equilibri entre el viure i el morir que, inevitablement, s'acaba decantant sempre del costat de la mort:

Viure és anar-se morint. I vet aquí per què una definició de mort que es basi en la vida serà un cercle viciós, ja que la vida no pot explicar-se sense la mort. (Diàlegs socràtics: 184)

En una vida com aquella en què creu Villalonga «el fat no és a les mans dels déus, sinó dins l'íntima contradicció dels homes; en llur voler i doldre. No menys inevitable tanmateix» (Llompart 1964: 12). Així, al llarg de la seva obra literària aquest patró heraclitià es reproduirà també en gairebé tots els seus personatges. Don Toni de Bearn, formulant, com vèiem més amunt, la teoria del món com una harmonia de contraris, n'és l'exponent més clar, ${ }^{21}$ però també el narrador de Flo la Vigne o el d'Andrea Victrix pateixen contradiccions semblants, i també l'irreductible Aquil-les és «colèric amb Agamèmnon, tendre amb Patrocle» (Bosch 1981: 163). Tots ells plantegen mons i munts de contradiccions que concorden amb les que turmenten Villalonga.

Com es pot veure, el pes d'Heràclit és relatiu, tal i com passa sempre amb les figures de la tradició clàssica en Villalonga. No és sinó una porta d'entrada des d'on Villalonga descabdella el seu món i el seu ideari. De fet, que Villalonga prengui la concepció de contraris d'Heràclit no vol dir, com ja hem vist, que sempre el citi directament, ni tampoc que el tingui present quan escriu els passatges que acabem de veure. No sabem ni tan sols si Villalonga comprenia enterament Heràclit. Tot apunta que no. Si més no, sembla que devia entendre l'Heràclit essencial, però que, com tants d'altres, no el podia assumir. És per això que Heràclit és, només, un punt de partença. Un cop Villalonga l'ha interioritzat - a la seva manera, és clar - es converteix en quelcom molt diferent a l'original, que és tractat amb molta ironia.

Per acabar d'esbossar la imatge que Villalonga tenia d'Heràclit, és convenient que vegem com el fa aparèixer en la clàssica contraposició entre el mateix Heràclit, el filòsof flens i Demòcrit, el filòsof ridens; contraposició que Villalonga utilitza com a metàfora de la seva vida i de la seva obra.

Sembla que el primer testimoni documentat d'aquesta famosa comparació és a Estobeu, i els mateixos Sèneca, a Sobre la ira, i Llucià, a la Subhasta de vides, en parlen. Tampoc no sembla que Villalonga hagués de conèixer aquests textos. Potser el de Sèneca sí, atès que era un autor que li interessava i que apareix aquí i allà en les seves obres. Més aviat, però, la idea d'introduir aquesta dualitat prové segurament un cop més, dels francesos. Probablement de Voltaire i Rousseau, que es llançaven els plats pel cap usant aquesta contraposició. Bosch també

\footnotetext{
21 «Don Toni pensava, somrient: "Per què han d'ésser incompatibles els hexàmetres llatins i fins els alexandrins francesos, amb les corretjades?". Reconeixia, però que començaven a semblar anacròniques en el segle XIX» (Bearn o la sala de les nines: 443).
} 
assenyala que potser havia llegit Campoamor, que havia tractat el tema, o Unamuno, que havia criticat el primer per fer-ho. ${ }^{22}$

En tot cas, a través d'uns o altres Villalonga conegué el tema segurament cap a finals dels anys seixanta, atès que l'utilitzà, que jo sàpiga, només dues vegades en obres pràcticament contemporànies, les Falses Memòries (1967) i en El Misantrop (publicat el 1972, però de redacció anterior):

Hi ha situacions a les quals no s'hi veu la sortida. Com un escorpí, el Nafta de Thomas Mann morí llançant la bava verinosa: "No us espereu que de tot això surti la llibertat; el que la Humanitat necessita, i el que tendrà, és el Terror". L'Eclesiastès s'havia expressat $\mathrm{d}$ 'una manera consemblant. I Heràclit. Però Demòcrit es salvà perquè sabé riure's un poc d'Heràclit. El símptoma més sospitós del nostre temps, potser el més greu és haver perdut la rialla. (Falses Memòries: 234)

Sí, arribaríem en aquestes conclusions monstruoses i a moltes altres, davant les quals és possible adoptar igualment la rialla de Demòcrit o les llàgrimes d'Heràclit.

-Si et sembla -decretà Salvador-, brindem per Demòcrit. (El Misantrop: 136)

Villalonga, irònic i sarcàstic, és evident que s'havia de decantar pel cantó de Demòcrit, que havia sabut riure davant l'adversitat, habilitat tan preuada per Villalonga i que ell mateix adoptava sempre que podia. Així succeeix en les dues ocasions esmentades, en les quals Demòcrit apareix victoriós perquè, com el mateix autor mallorquí, va saber enfrontar-se al món, caòtic i estúpid en tant que abocat a la subjectivitat $i$ a la mort, amb un somriure.

\section{BIBLIOGRAFIA}

AlZAMORA, S. (1999), «Drama i tragèdia dins el cicle de Fedra de Llorenç Villalonga i Salvador Espriu», a Actes del Col-loqui Llorenç Villalonga, Rosselló Bover, P. (ed.), Palma i Barcelona, Publicacions de l'Abadia de Montserrat.

BosCH, M. C. (1981), «Llorenç Villalonga entre Grècia i França», Randa, 11, 159-169.

BosCH, M. C. (1988), «El món clàssic d'en Llorenç Villalonga», Estudis Baleàrics, 29/30 (VIIX), 175-180.

BosCH, M. C. (1989), «El món clàssic d'en Llorenç Villalonga. Citacions gregues», Miscel-lània d'homenatge a Francesca Massot Villalonga, Palma, Conselleria de Cultura, Educació i Esports, 23-52.

BosCH, M. C. (1991), «Notes a l'entorn d'Helena d'Esparta de Llorenç Villalonga», Estudis Baleàrics, 40, 13-20.

BosCH, M. C. (1992), «El món clàssic d'en Llorenç Villalonga. Citacions llatines», Caligrama: revista insular de Filologia, 4, 155-183.

BosCH, M. C. (2007), «Alguns mites en tres escriptors mallorquins de postguerra», a Mites classics en la literatura catalana moderna i contemporània. Aula Carles Riba, Malé, J. i Miralles, E. (eds.), Barcelona, Publicacions i Edicions Universitat de Barcelona, 161-177.

$22 \operatorname{Bosch}(1989: 50)$. 
CABRÉ, R. (2007), «Aquil·les i Patrocle en Llorenç Villalonga», a Mites clàssics en la literatura catalana moderna i contemporània. Aula Carles Riba, Malé, J. i Miralles, E. (eds.), Barcelona, Publicacions i Edicions Universitat de Barcelona, 147-160.

CREus, E. (2017), «Els Diàlegs Socràtics de Llorenç Villalonga», Studia Philologica Valentina, 1, 209-218.

CREUS, E. (en premsa), «El Sòcrates de Llorenç Villalonga: La Xantipa», Ítaca.

CREUS, E. (2019), «La tradició clàssica en l'obra de Llorenç Villalonga: la influència de Zenó d'Elea», Estudios Filológicos y de Traducción, 1, 329-347.

ESPRIU, S. (1945), Antígona. Fedra, Palma, Editorial Moll.

FERRÀ-PONÇ, D. (1997), Escrits sobre Llorenç Villalonga, Palma i Barcelona, Universitat de les Illes Balears, Publicacions de l'Abadia de Montserrat.

MAS I CANALS, V. d. (2013), A propòsit del «Cicle de Flo la Vigne» de Llorenç Villalonga, tesi doctoral, Barcelona, Universitat de Barcelona. Disponible a: $<$ http://hdl.handle.net/10803/101463>.

MoreniLlA, C. (2015), «Helena de Vilallonga: referents i innovació», a TragèdiaT $\rho \alpha \gamma \omega \delta i \alpha$, Pujol Pardell, J. i Talavera, M. (eds.), Barcelona, Publicacions i Edicions Universitat de Barcelona, 311-332.

Olives Canals, J. (1952), Plató. Diàlegs IV, Barcelona, Fundació Bernat Metge.

PALAU IFABRE, J. (2007), La claredat d'Heràclit, Girona, Accent Editorial. (trad. per PonsatíMurlà, O.).

PòRTUlAS, J. I GRAU, S. (2012), Saviesa grega arcaica, Barcelona-Martorell, Adesiara.

RAGUÉ ARIAS, M. J. (1987), «El personatge de Fedra a l'obra de Llorenç Villalonga i de Salvador Espriu», D'art: Revista del Departament d'Història de l'Art, 13, 269-278.

SIMBOR RoIG, V. (2011), «De M. Bergeret a D. Toni de Bearn: Llorenç de Villalonga, ironista», Revista de Filología Románica, 28, 69-88.

VIDAl Alcover, J. (1965), «Pròleg a Desbarats», a Desbarats, Villalonga, Ll., Palma, Editorial Daedalus, 7-16.

VILLALONGA, Ll. (1964), Aquil·les o l'impossible. Alta i benemèrita senyora, Palma, Editorial Moll.

VILlALONGA, Ll. (1967), Falses Memòries, Barcelona, Club Editor.

VILlaLONGA, Ll. (1972a), El Misantrop, Barcelona, Edicions 62.

ViLlalONGA, Ll. (1972b), Flo la Vigne, Barcelona, Club Editor.

VillalONGA, Ll. (1973), Andrea Victrix, Barcelona, Edicions Destino.

VILLALONGA, Ll. (1980²), El llumí i altres narracions, Barcelona, Edicions 62.

VILLALONGA, Ll. (1986a), «La Xantipa», a Tots els contes I, Villalonga, Ll., Barcelona, Edicions 62.

VILLALONGA, Ll. (1986b), «Diàlegs socràtics», a Tots els contes II, Barcelona, Edicions 62.

VILlALONGA, Ll. (2014), El Cicle de Bearn, Barcelona, RBA La Magrana. 